\title{
Topografen Knud Aagaard.
}

\section{Af August F. Schmidt-}

Blandt vore ældre lokalhistoriske Skribenter indtager $\mathrm{Kn} \mathrm{ud}$ A a g a $r$ d en anset Plads, og da hans bedste Arbejder vedrører Sønderjylland, vil det være rimeligt, at også han bliver gjort til Genstand for Omtale i en biografisk Skildring i Sønderjydske Aarbøger.

Knud Aagaard var fra Kolding, hvor han blev født clen 22. Marts 1769 på S k in d e Iborg Lykke. Hans Forældre

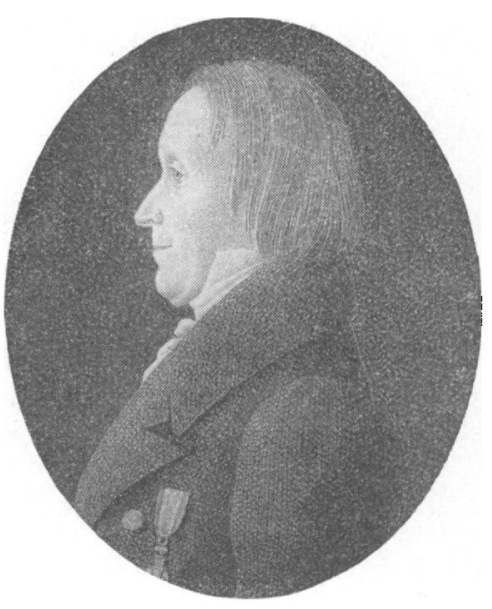
var Gartner (tidligere Klejnsmed og Blytækker) Svend Madsen Aagaard (171595) og Hustru Dorothea Lauritsen (ca. 1729-95). Ved Bortsalget af Ryttergodset, der hørte under Koldinghus Amt, i 1765 og senere, købte Svend Aagaard et Stykke Jord af det til Koldinghus hørende Landeri, beliggende Nord for Kolding Slotssø. Arealet hed Skindelborg Lykke, og den Part, Aagaard blev Ejer af, gav han Navnet $S$ k in de lborg Hauge. Herpå byggede han et Hus og anlagde en Have. I den dertil liggende Toft opryddede han Mursten af en gammel Bygning, der muligvis har været et Hus til Ladegården. Om dette Oprydningsarbejde hørte Knud Aagaard naturligvis ofte Tale i sin Barndom. I de udprægede historiske Omgivelser, hvori den lille Dreng voksede op, har han fået Sansen for Fortiden tidlig udviklet, og da hian i 50-Års Alderen nedskrev sine Erindringer om Skindelborg Lykke, ${ }^{1}$ ) kom han i

1) Antiquariske Annaler III, 1820, 253-265. Sammesteds fremkommer Aagaard med flere ikke uefne Bemærkninger om vore Stednavnes sproglige Forståelse. - En Broder til Aagaard, J. A a g a a r d, blev senere en kendt Kabmand i Kolding. 
sine Betragtninger, der havde en for Tiden god stedshistorisk Viden til Forudsætıing, til det Resultat, at der her Nord for Slotssøen i længst forsvunden Tid havde ligget en "Borg", s k i n d e l b o r g, der skulde være en ældre Bcrg end Koldinghus. Den nyere historiske Forskning har dog ikke givet Aagaard nogen Tilslutning. Der har ikke ligget nogen Borg Nord for Slotssøen ved Koldinghus. ${ }^{1}$ )

Knud Aagaard blev sat i Kolding Latinskole, og i 1789 blev han i Tyveårsalderen Student. Fem År senere, den 30. April 1794 blev han theologisk Kandidat ved Københavns Universitet. Den 4. September samme År blev han Alumnus på Elers' Kollegium, og endnu inden han havde fået Præsteembede, giftede han sig. Han blev den 27. Juli 1796 i København viet til Karine S ophie Schrøder, f. Rossouw, der havde været gift en Gang før, nemlig med Revisor i Generalpostamtet P e ter S c h røder (1736-76). Fru Aagaard var en Del ældre end sin Mand, idet hun blev født i København 13. April 1754 som Datter af Bagermester Joa c him Hin rich Ros o u w (c. 1712 -6i8) og Margaretha Brandt (c. 1720-68).

To $\AA \mathrm{r}$ efter sit Giftermål fik Aagaard Embede, idet han den 27. April 1798 blev udnævnt til residerende Kapellan i $T$ h is ted. Herfra forflyttedes han allerede, den 29. November 1799 til Sognepræsteembedet for Skjoldborg-Kaller u p Pastorat Syd for Thisted. Her forblev han i godt seks År.

I Skjoldborg døde Fru Karine Aagaard den 14. September 1804 efter 3 Ugers Mavesygdom. Hendes Grav er ved den vestre Ende af Skjoldborg Kirkes Våbenhus. En smuk Sandsten på en muret Sokkel er rejst på Graven, og på en i Sandstenen indsat Blyplade står hendes Navn og Dødsdag.") - Godt et Årstid efter sin Hustrus Dad var Pastor Aagaard lykkelig gift igen, denne Gang med en Sønderjyde. Den 12. Oktober 1805 blev han i Bøvling Kirke viet til Ingeborg S chack, født 10 . Februar 1772 på H arrisgård i B rede Sogn. Hun var Dat-

1) P. Eliassen: Kolding fra Middelalder til Nutid (1910), 9.

$\left.{ }^{2}\right)$ S. C. Sortfeldt: Præsterne i Skjoldborg (Historisk Aarbog for Thisted Amt 19:34, 469-70). 
ter af Gårdejer, senere Godsejer $\mathrm{N}$ i els $\mathrm{N}$ ielsen $\mathrm{Sch}$ a ck (1735-1810) og A n cke Christians (B e y e r) (1749-1801).

Allerede i 1802 kunde Pastor Aagaard udsende en Bog på 250 Sider om Thy, betitlet "Physisk, oeconomisk og topographisk Beskrivelse over Thye«. Arbejdet omfatter kun det egentlige Thy; $\mathbf{r}$. Han Herred og Mors er ikke skildret $i$ den nyttige Bog, der giver eit interessant Billede af Forholdene i Thy i sidste Halvdel af det 18. Arhundrede. "Beskrivelse over 'Thye" indeholder en Mængde fortræffelige kulturhistoriske og agronomiske Oplysninger og er Grundbogen i Udforskningen af denne forhen så ugæestmilde Landsdels Historie og Folkeliv. ${ }^{1}$ )

I Tilslutning til Thybeskrivelsen bør læses Knud Aagaards Afhandling: "Et Par Ord om Fattigvæsenet paa Landet", trykt i Iris og Hebe 1804, III, 73-92. Dette Bidrag er skrevet i Anledning af Loven af 5. Juli 1803 om Fattigvæsenet pâ Landı́t. Den socialt interesserede Skjoldborg-Præst fremdrager Eksempler på, hvorledes Fattigdommen på Landet kunde aftage, hvis Folk udnyttede $\mathrm{H}$ usfliden mere end tilforn. Han nævner som Emner for Hjemmeindustri Lobbinding, Træskolavning, Solde af Fåre- og Kalveskind, Fabrikation af Piberør, Stråhatte o. s. fr. I direkte Tilslutning til Værket om Thyland omtaler han Thybo-Ostene, Uldarbejde og Strømpestrikning og slutter med at udtale Håbet om, at de fattiges Kår må forbedres, nu da Regeringen med sin Lovgivning har vist sine gode Hensigter overfor de små i Samfundet.

Selv om Pastor Aagaard snart vandt et anset Navn i Thy, er det ikke noget at fortænke ham i, at han ønskede at blive forflyttet til blidere og mere centralt beliggende Egne. Det er muligt, at han med sit topografiske Værk om Thy var bleven så bekendt, at han af denne Grund kom i Betragtning, da A gerskov Præstekald (NørreRangstrup Herred) Vest for Åbenrå i 1806 blev ledigt. Han fik i hvert Fald dette Embede (kaldet 28. Marts 1806), som Kongen havde Kaldsret til, da det

1) Beskrivelsen over Thye fik en udforlig og anerkendencle Anmeldelse af Otto Lemvigh i Kjøbenhavnske lax re Efterretninger 1804 . Nr. 35-36. Lemvigh var Byfoged i Thisted 1789-92. 
lă i Tørning Le h n. Kongen kaldte herved en Præst til Hertugdømmet, der var fra Kolding, og som var udgået fra Københavns Universitet. Mange af de slesvigske Præster var ellers i hin Tid udgået fra Universitetet i Kiel.

Efter at have flyttet sin Familie og sine fleste Ejendele til Vogns den 33 Mil lange Vej fra Skjoldborg i Thy gennem den jydske Halvo i Løbet af 5 Dage, tiltrådte Knud Aagaard sit nye Fmbede ("nu endelig er vi ene og i Rolighed") og begyndte den stille Leven sig ind med sine Sognebørn, der her ligesom i Thy skulde afføde betydningsfulde Arbejder om Bondernes Liv og Tænkemåde. ${ }^{1}$ ) I Agerskov fik Aagaard sin egentlige Manddomsgerning, og her øvode han sin bedste Skribentvirksomhed. Hans forste store Arbejde hernede fra var Besvarelsen af en agronomisk Prisopgave: "Veiledning ved en Gaards Drift i Hedeegne«, trykt i Landhusholdningsselskabets Skrifter Ny Samling II (1811), 331-466; også udkommet som Bog (København 1811), anerkendende omtalt i Dansk Litteratur-Tidende 1814, 54-61; 1816, 184-87, 193-204.

"Veiledning ved en Gaards Drift i Hedeegne" er et fortrinligt agrarhistorisk Arbejde. Det er skrevet ud fra Knud Aagaards egne Iagttagelser, Erfaringer og Forsøg som Præstegårdsbesidder. En Mængde Oplysninger af betydelig landbrugshistorisk Værdi er at finde i det omfangsrige Arbejde, der giver den bedste Fremstilling, vi har, om Landbruget i Jyllands Hedeegne ved Begrndelsen af det 19. Aarhundrede. Pastor Aagaard, der som Landmand var forud for sin Tid, har sikkert gjort god Gavn med sin systematisk opbyggede Redegørelse for, hvorledes en Hedegård med mest Fordel kunde drives. Selv om man hele Tiden hører Forfatterens belærende Tale ("det bør være saaledes« o. s. v.), er det naturligvis en Selvfølge, at han bygger sin Fremstilling på direkte Landbrugsiagttagelser i Agerskovcgnen, (undertiden suppleret med Oplysninger fra Thy), hvorfor man trøstig tør tage Aagaards Arbejde som et almindeligt Udtryk for den bedste Del af Hedeegnens Landbrug i Sønderjyl-

\footnotetext{
1) Knud Fabricius i Sønderiyllands Historie IV, 35.
} 
land ved 1810. Da det $\mathrm{i}$ høj Grad betød noget at få den karrige Jords Ydeevue sat op, spillede Gødningsproblemet en lkke ubetydelig Rolle for Hedebønderne. Derfor har Aagaard da også indledet sit Arbejde med en Række omhyggelige Kapitler om Godningshjælpemidler i Hedeegne. Det er af ikke ringe landbrugshistorisk Interesse, hvad Aagaard meddeler om Lyng, Mos, Mergel, Ler, Aske og disse Tings Anvendelse som Godning. Om Godningens Formerelse har han også et larerigt Afsnit. Bemærkelsesvardigt er det, at Pastor Aagaard gor så nieget ud af Mergele $n$ og denne Jordarts Anvendelse ved Grundforbedring. Ogsã i sin Beskrivelse af Thy (1802, S. 108) meddeler Aagaard Oplysninger om Mergelens Brug i denne Landsdel, helt fra o. 17:0-30. I Agerskov, hvor Mergel forefin(les hyppig, har "man nu lart at giore Brug af den. Med hvert Aar tiltager Lysten og Virksomheden ved Mergelarbeillet« (S. 35(i-57), oplyser Forfatteren, der sikkert med sit Arbejde i udstrakt Grad har opmuntret Folk i denne Egn til at anvende Mergel, som man $i$ de fleste Dele af Danmark forst rigtig begyndte at udnytte omkring ved 1850 (jfr. min Bog: Nogle Arbejdsgilder i den gamle danske Landsby 1938, 40-41), Også om Agerdyrkningen har Aagaard en Række sagligt værdifulde Kapitler (om Rugmarkens Inddeling, Sæedskifte, Særlarter), hvorefter Kreaturholdet samt Fjerkræog Bier omtales. - Et så interessant Emne som Markfre d og H P g n har også haft den indsigtsfulde Præests Opmæarksomhed (se Afsnittet Ind he g n ing), hvorefter Haver, Træplantn ing cg H u s f l i d skildres.

Aagaards Arbejle var en betydelig Tilvakst til hin Tids "Landhusholdningslitteratur», og det har stadig agrarhistorisk Væroli. Det lases som et nyttigt Supplement til H. F. Fe i lbe r g s Folkelivsskildring: "Fra Heden« (1863), der omhandler Folkelivet på Hedesletten Vest for Flensborg. Medens Feilberg behandler det normale Folkeliv i alle dets Faser, er Aagaards Fremstilling en Skildring af, hvorledes et ideelt Landbrug skulde vare i Hedeegnene. Da Aagaard i Folge sit Emnes Af- 
grænsning ikke skriver on den immaterielle Kultur, er der en ikke ringe Forskel på hans og Feilbergs Arbejde fra 1863. Feilberg er i det hele mærkelig lidt påvirket af Aagaard. Det kunde dog se ud, som Feilberg har haft Aagaards Skildring af en T e glovn ("Veiledning«, S. 459) i Tankerne, da han i Dansk Bondeliv I (1889), S. 17 skrev om Teglovne i Sydvestjylland.

Aagaard ejer ikke Feilbergs lijertelige Fortællemaade, men han er derfor alligevel ingen ringe Skribent. Hans Stil er underholdende og flydende, og han har, som den gode rationalistiske Præst han var, uden Tvivl virket højnende paa Befolkningen i Agerskovegnen, der ingenlunde har haft Behov at gaa tilbage $i$ Kristenliv, fordi deres Præst ogsaa forstod at være dem en praktisk Vejleder, en Mand, der i Overensstemmelse med en tiltalende Tidsaand arbejdede for det "til Borgerheld sigtende". Betegnende for Aagaards humane Indstilling er, at han hørte til de Præster, der gik i Spidsen ved Gennemførelsen af Forordningen om $\mathrm{V}$ a c c in a tion. Han vaccinerede selv sine Menighedsmedlemmer, ${ }^{1}$ ) hvis Ve og Vel laa ham saa stærkt paa Sinde, og hvis menneskelige Dyder han forstod at vurdere. Han udtaler sig i varme og anerkendende Ord om de Hedeboere, han havde sin Virksomhed iblandt ("Vejledning«, S. 465), og det kan jo dog være, trods Forskellen i Livssyn, at de grundtvigske Folkemøder, der fra 1852 holdtes i M a nd bjerg Sk ov i Agerskov Sogn, ikke er uden Forbindelse med den baade verdslige og kristelige Oplysning, som Knud Aagaard søgte at indpode i Sindene i sin Agerskovtid 1806-1838. Jfr. Sprogf. Almanak 1899, 13.

Knud Aagaards mest bekendte Arbejde er Bogen: "Beskrivelse over $\mathrm{T}$ ørning $\mathrm{L}$ e h $\mathrm{n}$ " $(1815,312$ Sider $)$, et af de forste større egnshistoriske Arbejder fra Sønderjylland, vi besidder. Ligesom Aagaard har haft Gavn af at udnytte topografiske Værker som E. Pontoppidans "Danske Atlas« VII (1781) og Peder Rhodes "Haderslev Amts Beskrivelse" (17\%5), saaledes har ogsaa senere sønderjydske Topografer og

1) Knud Fahricius i Sønderjyllands Historie IV, 135. 
Lokalhistorikere som J. N. S $\mathrm{ch}$ m i d t (»Slesvigs Land og Folk" 1852), J. P. Trap ("Hertugdxmmerne Slesvig-Holsten " I-II 1864), C. C. L or e n z e n ("Rejseskildringer« 1877), J. Fa us b l ("Minder fra Agerskov" 1910), A. J. Marcussen (»Optegnelser fra Rødding By og Sogn« 1912), Th or vald Møller ("Paa Strejftog i Amtet« 1913) m. fl. med Udbytte kunnet udnytte Knud Aagaards indholdsrige og vel disponerede Bog. Heri gives straks til Indledning en almindelig Ovcrsigt over de Begivenheder, der har virket til at løsne eller knytte Baandet miellem Kongeriget Danmark og Hertugdømmet Slesvig. Derefter følger en Redegørelse for de mangeartede Retsforhold i borgerlige Sager i Sønderjylland, hvor slesvigsk og dansk Jurisdiction i Aarhundredernes Lob er bevet lovlig meget indfiltret $\mathbf{i}$ hinanden, hvilket ogsaa galder slesvigsk og dansk Autoritet i kirkelige Sager. ${ }^{1}$ )

Ogsaa den uhensigtsmassige Blanding af slesvigske Distrikter mellem hinanden giver Aagaard lærerige Oplysninger om. Nerefter kommer vi til det Afsnit i Bogen, der er mest almen kendt: "Det danske Sprogs Skjebne og Grændser» (S. 46-63, ogsaa trykt $i$ det af $\mathrm{Christian} M$ olbech redigerede Tidsskrift "Athenew IV, 1815, S. 435-49), hvori han skildrer sin Forbavselse over, at Folk, der er dansktalende, udviser stort Snobberi overfor Tysk. "Det er latterligt at erfare, hvorledes Stympere, som dog maaske kunde skrive nogenledes forstaaeligt i deres danske Modersmaal, uden Nodvendighed hellere vilde sammenflikke et ravgalt Brev, som de indbilde sig at være tydsk, fordi det ikke er dansk, og at forhutle tvende Sprog paa een Gang (S. 61). Meget værdifulde er de Oplysninger, Aagaard fremkommer med om det danske Sprogs Grænser og Sprogblandingen i Egnene, hvor Dansk, Tysk og Frisisk mødes. Præstens ivrige Artikel om det danske Sprogs Nedværdigelse gjorde intet Indtryk Syd for Kongeaaen, men Nord for den faldt hans Ord i modtagelig Jord-

1) Disse Enıner optog ogsaa J. N. Schmidt stæurkt, da han skrev "Slesvigs Land og Folk" (jfr. Sønderjydske Aarbøger 1937, 210). 
bund. Her var der i København allerede fra det 18. Aarhundrede af begyndt en national VækkeJse, der ganske vist hidtil i det væsentlige havde holdt sig til Kongeriget. En af Repræsentanterne herfor var Professor Laurids Engels toft. Han fik sikkert under Faavirkning af Aagaards Skrift hvis Sprogafsnit blev trykt i Majheftet af "Athene" 1815 -.- i Slutningen af 1815 Etatsraad Jacob Brøn num Scaven i u s til Gjorslev (1749-1820) til at udsæette en Prisopgave om det danske Sprogs tidligere Udstrækning i Sønderjylland, om Grundene til dets Tilbagegang og om de Midler, hvorved det "som Landets xldste almindelige Tungemaal, tillige kunde blive det almindelige offentlige Undervisnings-, Forhandlings-, og Rettergangs-Sprog, og Sønderjylland saaledes i Henseende til Sproget blive, hvad det forhen har været, en dansk Provinds«.

Der indkom tre Besvarelser, en paa Dansk af Professor E. C. Werlauff (1781-1871) og to paa Tysk, af Sognepræst i Breklum Niçlaus outzen (1752-1826) og af Præsten, Dr. E. C. K r us e (1764-1846). Bagge de to forste blev prisbelonnet og udkom sanımen i 1819 . Kruses blev trykt i Kiel. Den betydeligste er Werlauffs; ingen af dem gav nøjere betragtet nye Oplysninger om Sprogspørgsmaalet.')

I Forbindelse med Aagaards inciterende sproggeografiske Afsnit bør nævnes hans Kapitel: "Provinsielle Ord og Talemaader" (S. 2:0-231), hvori han har samlet en Række særlige sønderjydske Dialektord og Udtryk, ligesom han i "Beskrivelse over Thye" (S. 240-250) meddeler en Række »tybonitiske Ord og Talemaader". Til C. M ol bech s Dialect-Lexikon (1841) indsendte Aagaard en Ordsamling fra Agerskov Sogn, (se Lexi-

1) Marius Kristensen i Sonderjyllands Historie I, 84. Dansk biografisk Leksikon I (1933), 8 f. Knud Fabricius i Sonderjyllands Historie IV, 118-121, 125, 132. P. K. Thorsen: Afhandlinger og Breve (udgivne ved J. Byskov og Marius Kristensen) I (1927), 70. Karl Nielsen Bock: Niederdeutsch auf dänischem Substrat (1933), 266 f. Th. Erslew: Forfatter-Lexicon I (1843), 2 f. Supplement I, 1. - Jfr. "Dagen" 1834, Nr. 2\%6, hvor Aagaard har skrevet en Artikel om "den forunderlige Sammenblanding af det tydske og danske Sprog i det Slesvigske $\ll$. 
kon'et S. XXV'III), men det er dog først i H. F. F e il berg s »Ordbog over jydske Almuesmål« I-IV (1886-1914), at Aagaards Dialektsamling fra Agerskov og Thyland bliver fuldt udnyttet. Hvergang der $i$ en af denne valdige Ordbogs mange Artikler står Agersk. eller Thy, gælder det en Henvisning til Aagaards sproglige Optegnelser, der også ved deres forholdsvise Alder er af ikke ringe Vardi.

Efter det betydningsfulde Sprogafsnit følger et Kapitel om Tørninglehns Beliggenhed, Størrelse og Folketal. Heri fremkommer Aagaard med gode Oplysninger om det gamle Tørning Slot, om Lehnets og det senere Haderslev Amts administrative Historie, hvorefter anfores Oplysninger om Fladeindhold, ${ }^{1}$ ) Folketal, Plovtakster etc. Et stort og indholdsrigt Afsnit indeholder mangeartelle Bidrag til Kundskab om den borgerlige Forfatning, og ikke mindre er Fremstillingen om den kirkel ige Forfatning. I førstnavnte Kapitel findes silledes Oplysninger om den almindelige Retspleje, Skattevæsen, Hartkorn og Plovtakst, Landgildepenge, Toldvæsen, Brændevinsbrænden, Arveforhold, Udskiftning og Parcellering, Fattigvasen, Brandhjælp, Mål og Mnnt, de vanskelige Pengeår o. $1813 \mathrm{~m}$. v. Under kirkelig Forfatning omtales Rescripter og Recesser vedrorende gejstlige Forhold (også om den gejstlige Allministration), Præsternes Indkomster og Rettigheder i Torninglehn (heri mange lokale Detailler), Provsteemberlet i Torninglehn, Drgne og Skoleholdere, Præsteenkers Forsmrgelse, Kirkernes Indkomster og Vedligeholdelse $\mathrm{m}$. $\mathrm{m}$.

Herefter stifter man Bekendtskab med Aagaards nøgterne Skildring af Folkets Leve måde og Kultur. Han er i dette Kapitel Feilbergs Forgænger, og man læser selv nu med Interesse den Agerskovpræsts rigtige og nyttige Fremstilling af Folkelivet i Hedelandet Vest for Abenrå. Han beretter om Drikning af Kaffepunche, Bryllupper og Begravelser, "Fødemidler,

1) Om Tørninglehns Omfang se Afh. af Jenssen i Michelsens og Asluussens Archiv für Staats- und Kirchengeschichte III, 373 ff, jfr. Falcks Staatsb. Mag. VII. $1-53$ o. 369-410. 
Klædedragt, Huse og deres Indretning, religisse Forhold (Aagaard er imod Pietismen) og Skolevæsen.

Et følgende Afsnit: "Vindskibelighed" handler om Kniplingsindustrien, Strikning, Kulbrænding i Miler, Teglbrænderier (Teglovne), Kalkbrænderi, Håndværk og Handel. Side 166 nævner Aagaard, at en Del Husmænd fra Agerskovegnen om Efteråret drog til Marsken for at tærske Korn i nogle Uger. Herved kunde de tjene gode Penge. Især drog de over til $\mathrm{Pe}$ ]v o r m. Her udsatte de sig dog for denne Ø's farlige Koldfebre, som kostede adskillige Sundhed og Liv. Det kan måske være af Interesse hertil at $f \circ j e$, at $i 1931$ fortalte en gammel Mand $i$ L a d e l u n d (Kixr Herred) syd for den nuværende Statsgrænse, at i hans Drengetid (o. 1860-70), drog Arbejdsmænd fra Ladelundegnen til Pelvorm for at tærske, men de kom tit tilbage med den pelvormske Sygen (egen Opt.).

Aagaard fortæller endvidere om Tørninglehns Naturforhold, Brændsel, Tørv og Skov, Agerdyrkning og Høbjærgning, Haveayrkning, Husdyr, Jagt og Fiskeri. Til disse Afsnits Udarbejdelse såvel som til Skildringen af de industrielle Talenter i Kapitfet "Vindskibelighed" har Aagaard i det væsentlige kunnet bruge, hvad han havde fremsat i Arbejilet: "Veiledning ved en Gaards Drift i Hedeegne" (1811). I Arbejdet fra 1811 er de betræffende Afsnit naturligvis meget udførligere end i Beskrivelsen af Tørning Lehn (jfr. "Veiledning«, S. 343-44, "Tørning Lehn«, S. 199, "Vejledning «, S. 350-368, "Torning Lehn«, S. 172, 206-201; "Veiledning«, S. 455-465, "Tørning Lehn«, S. 157-168).

Af gamle Dokumenter, Aagaard har offentliggjort i sin Lehnsbeskrivelse, skal nævnes A gerskov Grandebrev fra 1592, der senere er blevet optrykt i Danske Vider og Vedtægter III, 9-12. Andet Hovedafsnit af Aagaards Bog indeholder kortfattede Skildringer af Sognene i Herrederne Frøs, Kalslund, Gram, Nørre-Rangstrup og Hvidding (S. 25(i-312). I disse for deres Tid meget nyttige Sognebeskrivelser er der fortrinsvis givet Arealoplysninger, Statistik og Enkeltheder om Jordbundens Beskaffenhed. Lokalhistorikere, der agter at skrive grun- 
dige Sognebøger fra de nævnte Herreder, bør ikke undlade at se, hvad Alagaard har tilvejebragt fra Tørninglehns Sogne. Hans Meddelere har antagelig været Præsterne. Fra $\mathbf{R} ø \mathbf{d}$ d i n g Sogn er der således Oplysuninger om Pastor Taxen s Opdyrkningsarbejde og Mergelfolsøg (S. 2(34), og således kan der fremdrages flere Eksempler fra de små Sognebeskrivelser i Aagaards Bog, der gør dem berettigede til at blive omtalt sammen med Varkets ovrige Partier af mere almen Art.

Bogen om Torning Lohn fik naturligvis en smuk Modtagelse i Pressen. Den blev således gjort til Genstand for en længere Anmeldelse - nærmest et rosende Referat - i Dansk LitteraturTidende 1820, Nr. 34-35, S. 529-544, 551-53.') Den 28. Oktober 1817 blev Pastor Aagtaard udnævnt til Ridder af Danebroge, en rderst velfortjent Orden til den Præst i Sonderjylland, der $\mathbf{i}$ Frederik den Sjettes Tid gav os de bedste stedshistoriske Arbejder vedrørende Landet Syd for Kongeåen.

Endnu et stort Arbejde er der at næevne fra Aagaards Hånd. Han udgav i 1827 en "Christelig Haandbog for Quindekønnet af alle Stænder" (236 Sider), hvori han i en Række Kapitler meddeler moralsk belærende Vejledning for Kvindekønnet $i$ alle Livsstillinger og i mange af Livets Forhold. Her er Afsnit om Datterens Forhold til Forældrene, om Tjenestepigen, Kydskhed, Opskrifter til Pigens Morgen- og Aftenbøn, Kapitler om Hustruens Forhold til sin Mand, huslig Lyksalighed, uheldigt Agteskab, Børneopdragelse, Modgang og huslige Sorger, den frugtsommeliges Bøn, Konens Morgen- og Aftenbøn, Enkens Bøn o. m. m. Bogen er rationalistisk præget og synes ufolkelig. Den stiller ofte ret stærke Krav til Kvindfolkene (se således Afsnittet »Kydskheden«); Stilen er udførlig og vel gejstlig, Moralen præget for meget af en spidsborgerlig-banal Tankegang, og da Bogen er en belæst og tanksom Mands Arbejde, er den blottet for Humor, det, som ofte forsoner os med de gamle religiøse Skribenter fra det 17.--18. Århundrede, der i deres naive

1) Jfr. Allg. geogr. Ephemeriden 1816, April, S. 45i-61; Erg. Bl. z. Allg. H. Z. 1822, S. $713 \mathrm{ff}$. 
Snaksomhed kan virke både underholdende og fornøjelige, som f. Eks. Kirkehistorikeren Th s. L i l l e l u n d (1712-1781).

Mindre Arbejder af moralsk religies Art har Aagaard leveret i Afhandlingerne: "Kan Krig have Sted i en V'erden, som staar under et guddommeligt Forsyn? Og hvad Haab tor vi gjøre os on en evig Fred? (Athene IV, 497-530). "Et Par Ord til Mægling imellem Fornuft og Tro" (i Mollers Nyt theologisk Bibliotek XVIII, 1-54). ${ }^{1}$ ) »Om det Onde i Verden« (Smsts. XX, 171-98)."2) "Om Sygehuse i Middelalderen « (Apenrader Wochenblatt 1831, Nr. 754). Afhandlingen "Kan Krig have Sted... kan man godt læse med Udbyttie. Den indeholder gode, begavede Betragtninger og mange Sammenligninger mellem Menneskene cg den øvrige Natur (navnlig Dyre- og Planteriget). Aagaard tror næppe på Krigenes Afskaffelse, mell han fordommer dem. - I Recensionen i Dansk Litteratur-Tidende 1832, Nr. 45, S. 712 -13 om det onde i Verden omtales Pastor Aagaard som »den kundskabsrige og agtværdige Forfatter", der vel ikke i sit Arbejde har fremstillet ncgen ny Synsmåde, men dog har leveret mange interessante Bemærkninger, der vidner om en ualmindelig Iagttagelsesevine og udbredt Bekendtskab til Naturens V'irkninger. Aagaard bliver log også kritiseret. Han har efter Anmelderens Mening ikke opfattet Begreberne Fornuft og Tro rigtigt.

Det er rimeligt, at en så fordelagtig kendt Landsbypræast som Knud Aagaard kunde komme i Betragtning ved hojere Lmbedstildelinger, og det kunde jo ikke være nere passende, end at Forfatteren til Tøminglehns Beskrivelse, da Herredsprovsteembedet over Tørning Lehn blev ledigt, udnæuntes til Frovst for dette Distrikt (den 28. Januar 1829). Hans Provsti kom til at række over Frøs, Kalslund, Gram, Nr. Rangstrup og IIviding Herreder i Ribe Stift, så her blev noget at tage fat på for den virksomme Mand.

Af det Billede, der findes af Knud Aagaard i Sønderjyllands Historie IV, S. 35, ses det, at han har været en smuk Skikkelse

1) Recenseret i Litteratur-Tidende 183:), Nr. 42, S. 65\%-60.

2) Recenseret smsts. 1832, Nr. 45, S. 712-13. 
med et fint og klogt Ansigt. Jø r g e n F a u s bø l, der har kendt Folk, som var samtidige med Provst Aagaard, fortæller i sin Bog: "Minder fra Agerskov Sogn" (1910), 58 ff, at Provsten, der i mangt og meget var forud for sin Tid, var en høj Mand med et alvorligt og strengt Væen. "Hans Omdømme er vel en Del forskelligt, men han mindes endnu af alle med stor Arefrygt. Der er paastaaet, at han var Amtmand Johansens højre Haand, og der skete ikke noget i V'esteramtet, uden at Aiagaards Mening først var hørt. Han var i det hele Omegnens Orakel og blev spurgt til Raads i alle vanskelige Tilfælde. Aagaard var meget sparsommelig,") Folk mindes endnu [o. 1910], at til Hans Refslunds Bryllup i Bovlund bestod hans Datters Pynt kun af blaa Kornblomster. $\left.{ }^{2}\right)$ Som enhver kraftig Personlighed blev han beskyldt for at være herskesyg; og den Uvilje, han plaadrog sig ved saa egenmægtigt og hensynsløst at indføre den „Evangeljske Salmebog", er fuldtud ber'ettiget og kaster ien mørk Skygge paa den foretagsomme Mands Minde«.

Disse sidste Ord af Jørgen Fausbøl synes lovlig hårde, når man tager Tidsforholdene i Betragtning. Pastor Aagaard var en lovlydig og loyal Præst, der ikke kunde tænke sig at sætte sig imod Indførelsen af en Salmebog, som der fra oven af var udstedt Lovbestemmelse om fremtidig Brug af ved det officielle kristelige Arbejde i vort Land. - En stor Del af Sognefolkene i Agerskov kundie ikke tænk» sig at bytte Kingos Salmebog med den evangelisk-kristelige; de sendte derfor en Klage herover til Kongen. Den 13. April 1813 lod det danske Kancelli tilkendegive, at der ikke kunde agtes på Klagen, og den nye Salmebog blev altså her - som andre Steder - inidført ved den offentlige Gudsdyrkelse, hvilket har passet Aagaard godt, idet han den 29. Novbr. 1812 på Prædikestolen sagde, at han anså det for sin Pligt at burde bidrage sit 'til at bringe den evange -

1) Jfr. hermed hans stærke Opmuntring til Selvhjælp på alle mulige Områder, navnlig til Sparsommelighed, Husflid, Indførelse af Rodfrugter, Brugen af Mergel og Tørvejord til Strøelse.

2) Dette Træk behøver ikke at tyde på Sparsommelighed, da Blomsterpyntning på den Vis var en Mode i Romantikkens Tidsalder. 
lisk-kristelige Salmebog i Brug i sit Sogn. Trods Modstand blev han sin forste Bestemmelse tro. $\left.{ }^{1}\right)$ Befolkningens Kamp mod den nye Salmebog må ses i Sammenhæng med den religiøse Væk k e ls e, der i Arene o. 1813 havde bredt sig op i Sønderjylland. I Bondestanden havde Rationalismen aldrig fået fast Rod. Derfor var man imod en Salmebog med rationalistisk Præg. I Agerskov, som andetsteds i Sønderjylland, hvor Befolkningen viste en lignende Stemning mod den nye Salmebog, drev man - som lovlydige Borgene ikke Modstanden til Yderligheder, men dell jævne Mand lagde dog i Protesterne for Dagen, at det for ham her drejede sig om en Hjertesag, som han ikke godvillig vilde slippe. ${ }^{1}$ )

Pastor Aagaard førte i Agerskov Da g b og over sine Oplevelser og Iagttagelser. Bogen ejes af Fuldmægtig Jak. Grauer ng er udnyttet af Professor K n u d F a b ri c i u s i hans store og prægtige Fremstilling af Sønderjyllands Historie i Tiden 18051864 ("Sønderjyllands Historie«, Bind IV). Heri vil man finde udnyttet Optegnelser af mere almen Interesse, men derfor vil der alligevel være Grund til at udgive dens Hovedindhold, hvilket antagelig vil ske i Sønderjydske Aarbøger 1939. I de Omgivelser, Dagbogen er citeret i Sønderjyllands Historie IV, kommer dens Indhold rigtig til sin Ret. Den indeholder meget om Krigen 1807-14 (se Sdj. Hist. IV, S. 63, 68, 72, 82, 86, 87, 88) og bringer gode Enkeltheder om Landbrugsforhold og Handel i de vanskelige År omkring 1810 (se Sdj. Hist. IV., S. 74, 76, 82 Pengesager, 94, 517 Rugpriser). Om Landbrugskrisen, der slog ind 1818, skriver Aagaard i sin Dagbog så tidlig som i 1819: "Mangel paa Penge, Næring og Handel føles i alle Lande. Denne Egn og hele Danmark forarmes Aar efter Aar"; 1821: "Velstand aftager, Fattigdom tiltager næsten i alle Stænder" (Sdj. Hist, IV, 141). I 1833 kunde Pastor Aagaard opgive sine Indtægter for 1832 til:

1) J. Fausbol: Minder fra Agerskov Sogn (1910), S. 60-63, hvor Salmebogsstriden er omtalt. Jfr. Sonderjydske Aarloger 1909, 67.

$\left.{ }^{2}\right)$ Knud Fabricius i Sonderjyllands Historie. IV, 115, 519. 
Præstekald og Avling ........ 1006 Rdl. 2 Mrk. 14 Sk., Provsteemberlet ............ 194 Rdl. 2 Mrk. 2 Sk., mens Udgifterne var ....... 725 Roll. 0 Mrk. 14 Sk.

Det var mange Ar siden, han havde siddet så godt $\mathrm{i}$ det (Sdj. Hist. IV, 180) så nu var efter Krisetiden begyndt den Opgang for det danske Landbrug, der skulde vare ved gennem lange Tider.

I April 1816, da Aagaard var fyldt $47 \AA$ Ar, skrev han en Skildring af sig selv, der ved sit tidstypiske Præg har gjort sig fortjent til at blive trykt i Sønderjyllands Historie IV, 35-36. Her stifter man vel ikke Bekendtskab med nogen høj og fribåren And, men med en ærlig Mand, der i sine Betragtninger, som Prof. Fabricius med Rette fremhæver, giver Udtryk for, hvad mange Præster mente. Han står i så Fald som et godt Udtryk for den Ånd, soin Befolkningen i Sønderjylland i Frederik den Sjettes Dage mødte hos sine åndelige Vejledere.

Provst Aagaard døde i Agerskov den 27. Februar 1838. Hans Hustru overlevede ham til den 19. September samme År. De hviler begge på Agerskov Kirkegård.

Den 10. 6. 1938.

August F. Schmidt. 